\title{
Consumer Finance and Social Indicators in China
}

\author{
Li Liao $\cdot$ Jing Jian Xiao
}

Accepted: 20 December 2013/Published online: 8 January 2014

(C) Springer Science+Business Media Dordrecht 2013

Consumer finance as an emerging field draws attention of researchers from diverse fields such as economics, finance, and consumer science (Campbell 2006; Tufano 2009; Xiao 2008). Important social indicators show societal progress and quality of life and can be measured by both objective and subjective measures (Michalos 2008; Sirgy et al. 2006). In consumer finance, important objective indicators include consumer income, expenditure, debt, asset, and various combinations of these indicators. These indicators are all related to consumption: income can be used for both current and future consumption, expenditure is a measure of current consumption, debt is used to finance current consumption, and asset is accumulated to secure future consumption. Another set of important objective indicators of consumer finance is consumer financial behavior. Parallel to key consumer finance indicators, these behaviors include earning, spending, borrowing and saving. Being able to perform desirable financial behaviors with adequate financial literacy to achieve desirable financial goals is considered consumer financial capability (Taylor 2011; Xiao 2011; Xiao et al. 2013) that is closely related to consumer financial well-being. Financial well-being is achieved when desirable levels of these indicators are obtained. Financial well-being can also be measured by subjective measures such as financial satisfaction and satisfactions of other financial indicators such as income, spending, borrowing and saving. Consumer finance as an important life domain is closely related to quality of life and subjective wellbeing such as happiness and life satisfaction.

Consumer finance research as a field in China is emerging too. China has started its economic reform and open-door policies since 1978. The Chinese economy is growing to the second largest in the world. Consumer life becomes much richer than before and consumer finance has been more complicated compared to the situation 35 years ago. To

\footnotetext{
L. Liao

PBC School of Finance, Tsinghua University, Beijing 100084, People's Republic of China e-mail: liaol@pbcsf.tsinghua.edu.cn

J. J. Xiao $(\bowtie)$

Department of Human Development and Family Studies, University of Rhode Island, Kingston, RI 02881, USA

e-mail: xiao@uri.edu
} 
promote consumer finance as a promising new field, The Tsinghua University Center of Financial Research in recent years has sponsored several research forums and published several special issues in Economic Research, the top economic journal in China, on this important topic (e.g. Wang et al. 2010; Liao and Zhang 2011). In addition, the same center has conducted national surveys among urban households, the China Consumer Finance Survey, in both 2009 and 2010 (Liao et al. 2009; Liao and Zhang 2010). The symposium presented here is the first of this kind in English to examine important consumer finance and social indicator issues faced by Chinese consumers. Hope this symposium will stimulate future research interests in this important and emerging field and enrich the consumer finance and social indicator literature worldwide. Following are brief descriptions of articles included in the symposium.

Two articles relate micro economic indicators to subjective well-being. Gao, Meng and Zhang studied the association between fiscal decentralization and life satisfaction from a perspective of public finance, using multi-year datasets of the China General Social Survey combined with macro data from several sources. They found that greater revenue decentralization increases life satisfaction; revenue decentralization is more important to the underdeveloped western region, the private sector employees and homeowners; and both the rich and poor gain from revenue decentralization. Chen, Li, Shi and Zhou examined the effect of inflation on life satisfaction. Analyzing life satisfaction data from the 2010 Chinese General Social Survey combined with inflation data from several statistics yearbooks, they found that on average, a 0.1 percent rise in inflation rate will cause a welfare loss of about 73.0-164.1 RMB, mainly from unexpected inflation. Effects of inflation have greater negative impacts on lower income groups and different income groups receive different impacts on different commodities.

Income satisfaction is closely related to consumer financial well-being. Zheng, Wang and Song conducted a case study using data from a state-owned science institute in China to examine pay satisfaction of employees after the pay system reform. They found that pay satisfaction has significantly improved after the pay system reform that focused on equity. Based on their research, four dimensions of equity - individual, internal, procedural, and external, have significant positive effects on the overall pay satisfaction.

Stock market participation is another important indicator for consumer financial wellbeing. Xia, Wang and Li explored the relationship between financial literacy overconfidence and stock market participation with data from the 2012 Chinese Survey of Consumer Finance. Financial literacy overconfidence is defined by the positive difference between subjective and objective financial literacy. They found that financial literacy overconfidence is positively correlated with stock market participation.

When the world is entering the aging society, quality of life of elders is concerned by people in many countries including China. Cai, Yang and Guo conducted cluster analyses among elders using data collected by the China Research Center on Aging. They found that Chinese seniors can be divided into two basic, distinct segments, helpless dependents and active independents. Helpless dependents expect their children to take care of their retirement life while active independents rely mainly on themselves to secure a comfortable retirement.

Acknowledgments We would like to thank Alex Michalos, the editor-in-chief of Social Indicators Research, for giving us the opportunity to prepare for this symposium. Without his guidance and encouragements, it is impossible for us to accomplish this important task. We also thank Zhengwei Wang at Tsinghua University who served as an important liaison for us to contact authors for important revisions and communications. Thanks also go to Zhe Song at Tsinghua University, who handled numerous emails to facilitate communications between the authors, reviewers, and guest editors. Specially, Li Liao appreciates 
the support from the National Science Foundation of China for his research projects on consumer finance in China (Projects No. 71232003). We also thank Fuzhong Chen, Cheng Chen, and Lei Sun, who are Ph.D. students from Renmin University of China and visiting scholars at University of Rhode Island in 2013, for providing valuable assistances in the manuscript reviewing process. Appreciation goes to Sha Jin who helped reference checking. Finally, we thank reviewers who devoted their time and energy and provided detailed and helpful anonymous reviews that helped improve the quality of the manuscripts greatly. They are: Yi Cai, Liyan Han, Weida Kuang, Tao Li, Zhisheng Li, Xiangyi Meng, Shunfeng Song, Weixing Wu, Zuoping Xiao, Rui Yao, Tong Yu, Lishu Zhang, and Xueyong Zhang.

\section{References}

Campbell, J. Y. (2006). Household finance. Journal of Finance, 61(4), 1553-1604.

Liao, L., \& Zhang, J. (2010). China survey of consumer finances. Beijing: Economic Science Press. (in Chinese).

Liao, L., \& Zhang, J. (2011). Economic status, financial awareness, and borrowing behavior of urban households: A study of consumer finance in 24 cities in China. Economic Research, 46(s1), 17-29. (in Chinese).

Liao, L., Zhang, J., \& Huang, R. (2009). China survey of consumer finances. Beijing: Economic Science Press. (in Chinese).

Michalos, A. C. (2008). Education, happiness and wellbeing. Social Indicators Research, 87(3), 347-366.

Sirgy, M. J., Michalos, A. C., Ferriss, A. L., Easterlin, R. E., Patrick, D., \& Pavot, W. (2006). The quality-of life (QOL) research movement: Past, present, and future. Social Indicators Research, 76, 343-466.

Taylor, M. (2011). Measuring financial capability and its determinants using survey data. Social Indicators Research, 102(2), 297-314.

Tufano, P. (2009). Consumer finance. Annual Review of Financial Economics, 1(1), 227-247.

Wang, J., Liao, L., \& Zhang, J. (2010). An overview of consumer finance research. Economic Research, $45(\mathrm{~s} 1), 5-29$.

Xiao, J. J. (Ed.). (2008). Handbook of consumer finance research. New York: Springer.

Xiao, J. J. (2011). Consumer financial behavior, financial education, and well-being. Economic Research, 46(S2), 4-16. (in Chinese).

Xiao, J. J., Chen, C., \& Chen, F. (2013). Consumer financial capability and financial satisfaction. Social Indicators Research. Online First. Doi: 10.1007/s11205-013-0414-8. 